\title{
Charge moment change and lightning-driven electric fields associated with negative sprites and halos
}

\author{
Jingbo Li, ${ }^{1}$ Steven Cummer, ${ }^{1}$ Gaopeng Lu, ${ }^{1}$ and Lucian Zigoneanu ${ }^{1}$ \\ Received 15 March 2012; revised 30 July 2012; accepted 30 July 2012; published 18 September 2012.
}

[1] Sprites are structured high altitude optical emissions produced by lightning-driven electric fields. Both strong positive and negative cloud to ground flashes (CGs) are capable of initiating sprites. However, reported sprites are almost exclusively produced by + CGs. The very limited number of negative polarity sprites makes it difficult to reveal their morphologies and mechanisms. Since 2008, we have operated low light cameras at 5 locations in the United States to detect lightning-driven transient luminous events (TLEs). At Duke University, two pairs of magnetic sensors simultaneously record lightning-radiated magnetic fields. During 4 years of observations, the low light cameras collectively captured 1651 sprite events. Among them, 6 were produced by -CG lightning, which was confirmed by both the National Lightning Detection Network (NLDN) and magnetic field measurements. All of these negative sprites show similar features in their morphology, lightning source current, and lightning-driven ambient electric fields. They all initiate within a few ms from their parent lightning discharges and always are accompanied by sprite halos. Compared to positive sprites, the downward streamers in negative sprites terminate at higher altitudes, about $55-60 \mathrm{~km}$. The extracted source current of their parent lightning discharges is very impulsive and produces at least $450 \mathrm{C} \mathrm{km}$ charge moment change in $0.5 \mathrm{~ms}$ or less. Unlike most $+\mathrm{CG}$ strokes, essentially no continuing current follows these -CGs. Thus the uniformity of negative sprite morphology appears to reflect the uniformity of the characteristics of high charge transfer negative strokes. Numerical simulation shows these impulsive source currents produce very high ( $>2 E_{k}$, where $E_{k}$ is the local air breakdown field) but short-lived electric fields at halo altitudes between $70 \mathrm{~km}$ and $90 \mathrm{~km}$. At streamer termination altitudes, the inferred background electric field is $0.2-0.3 E_{k}$, which is close to but below the critical field $\left(0.4 E_{k}\right)$ for negative streamer propagation. The simulations also show that the timescale of the lightning source current has a significant impact on the high altitude electric fields and thus the sprite initiation and morphology. With the same amount of charge transfer, a more impulsive current source produces a higher electric field of shorter duration at halo and sprite altitudes. The short timescales may explain why a larger threshold of total charge moment change is required to initiate negative sprites than short-delayed positive sprites, whose parent lightning source current is usually less impulsive.

Citation: Li, J., S. Cummer, G. Lu, and L. Zigoneanu (2012), Charge moment change and lightning-driven electric fields associated with negative sprites and halos, J. Geophys. Res., 117, A09310, doi:10.1029/2012JA017731.

\section{Introduction}

[2] Sprites are structured optical emissions in the mesosphere produced by lightning discharges and are observed between $\sim 40-90 \mathrm{~km}$ altitude above thunderstorms [Sentman et al., 1995]. Previous measurements of sprite optical emissions have revealed its fine streamer structure by telescope

\footnotetext{
${ }^{1}$ Department of Electrical and Computer Engineering, Duke University, Durham, North Carolina, USA.

Corresponding author: J. Li, Department of Electrical and Computer Engineering, Duke University, Durham, NC 27708, USA. (jingbo.li@duke.edu)

C2012. American Geophysical Union. All Rights Reserved. 0148-0227/12/2012JA017731
}

[Gerken et al., 2000; Gerken and Inan, 2002] and by high speed videos [Stanley et al., 1999; Stenbaek-Nielsen et al., 2000; Cummer et al., 2006; McHarg et al., 2007]. A diffuse region is often observed at the top of a sprite [Stanley et al., 1999, 2000; Wescott et al., 2001], which is now classified as a halo [Barrington-Leigh et al., 2001].

[3] According to the largely accepted conventional breakdown model [Pasko et al., 1997], both halos and sprites are produced by high altitude lightning-driven electric fields. Early and recent numerical models showed polarity independence in the ability of +CGs and -CGs to trigger halos and sprites [Pasko et al., 1997, 1998; Asano et al., 2008, 2009]. This modeling also pointed out the difference in the initiation mechanism of halos and sprites. Halos are promptly produced 
when the normalized electric field $\left(E / E_{k}\right)$ is high enough to produce diffuse optical emissions, where $E_{k}$ is the local air breakdown field [Wilson, 1925]. Initiation of a sprite requires both a high field region of $E>E_{k}$ and the persistence of this high field to form the streamer structure [Liu and Pasko, 2004]. Numerous observations have shown that sprites can occur with and without a halo and vice versa [Cummer et al., 2006; McHarg et al., 2007; Li et al., 2008; Li and Cummer, 2009].

[4] More recent modeling [Qin et al., 2011] indicates that the initiation mechanisms for negative and positive halos are the same but that the streamer initiation region is different for $-\mathrm{CGs}$ and $+\mathrm{CGs}$ due to their different $\mathrm{E}$ field polarities. This model also predicts that downward streamers in negative sprites should be dimmer than upward streamers due to a higher critical field and thus a smaller development region comparing with positive sprites.

[5] It is difficult to test these theories as sprites produced by -CGs are extremely rarely observed. Among many thousand sprites detected globally, only three negative sprites are confirmed without ambiguity [Barrington-Leigh et al., 2001; Taylor et al., 2008]. All three events are prompt sprites that follow soon after a lightning return stroke, and are associated with charge moment change greater than $500 \mathrm{C} \mathrm{km}$, which is higher than the empirical threshold for typical positive sprites about $300 \mathrm{C} \mathrm{km}$ [Huang et al., 1999; Hu et al., 2002; Cummer and Lyons, 2005]. On the other hand, negative halos are commonly detected. [Newsome and Inan, 2010] reported a similar occurrence rate for halos generated by + CGs and - CGs. Results from [Bering et al., 2004; Frey et al., 2007; Williams et al., 2012] shown that negative halos may be more common than positive halos.

[6] One reason for the rareness of negative sprites is that fewer-CGs can produce large total charge moment change [Pasko et al., 2000; Williams et al., 2007; Lu et al., 2012]. Although - CGs are much more numerous than + CGs, the ratio of $-\mathrm{CGs}$ to $+\mathrm{CGs}$ producing charge moment change greater $600 \mathrm{C} \mathrm{km}$ was 1:30 in one sprite-producing storm [Cummer and Lyons, 2005]. Broader observations [Williams et al., 2007] reported that the ratio of -CGs to +CGs producing more than $500 \mathrm{C} \mathrm{km}$ is $5-10 \%$. Negative strokes with such large impulse charge moments can almost be produced exclusively by two unusual types of negative CG lightning that both develop high level negative leader progression before spawning the intense negative CG stroke [ $L u$ et al., 2012]. These results partially explain the rareness of negative sprites but do not fully explain why negative sprites are so uncommon [Williams, 2006; Williams et al., 2007].

[7] In this work, we describe 6 negative sprite events observed among 1651 sprites detected by several cameras. We report the associated lightning current moment waveforms and estimate the high altitude lightning-driven electric fields. All of these negative sprites shown similar features in their morphology. They all occurred within a few ms from their parent lightning discharge. The sprite images show that all negative sprites follow halos and have a remarkably consistent structure, unlike their more variable positive polarity counterparts.

[8] By extracting the lightning source current from broadband $(0.1 \mathrm{~Hz}$ to $25 \mathrm{kHz})$ magnetic field measurements, we find in all cases that the parent lightning current source is very impulsive and creates a large moment change greater than $450 \mathrm{C} \mathrm{km}$ within $0.5 \mathrm{~ms}$ or less. Thus the lack of variability of negative sprite morphology appears to reflect the lack of variability in the nature of high charge transfer negative strokes, all of which are very impulsive and lack significant continuing current. This impulsive source produces very high electric fields at high altitudes from 70 $90 \mathrm{~km}$ and thus is responsible for the short time delay and sprite halos. At streamer termination altitudes, the electric field is about $0.2-0.3 E_{k}$, which is close to the lab-measured critical field for negative streamers $\left(0.4 E_{k}\right)$ and significantly higher than the $\sim 0.1 E_{k}$ sprite streamer termination field for positive streamers [ $\mathrm{Li}$ and Cummer, 2012].

[9] With numerical simulations, we also show that the lightning discharging timescale has substantial impact on the ambient electric fields and thus the negative sprite initiation and morphology. With the same amount of charge transfer, a more impulsive current source can produce higher electric fields of shorter duration at halo and sprite altitudes. The short timescale may explain the higher threshold required to initiate negative sprites than short-delayed positive sprites, whose parent lightning source is usually less impulsive.

\section{Experiment and Method}

[10] Beginning in 2008, we have operated low light cameras at 5 different stations in the United States to continually record sprites at night. The first observation system was built at Duke University in Durham, NC and started operation from January 2008. In 2009, an observation system was deployed in Hawley, TX. Three more stations were added in 2011 at Bennett, CO, Lubbock, TX and University of Mississippi, MS. Each system above includes a WATEC $902 \mathrm{H}$ low light camera, hardware and software to capture images in a triggered mode, and GPS units to provide absolute timing. The camera exposure time is $17 \mathrm{~ms}$. These sprite videos allow us to estimate the sprite altitude range by applying the background star field [Li and Cummer, 2009]. With observation from a single station, we have assumed that sprites occurred directly above their parent lightning discharge. The unknown radial separation (a few tens of $\mathrm{km}$ [Sentman et al., 1995; Lyons, 1996; Wescott et al., 1998, 2001]) contributes an overall altitude uncertainty of approximately $\pm 3 \mathrm{~km}$ for every $\pm 10 \mathrm{~km}$ change in radial offset for lightning $300-400 \mathrm{~km}$ away from the observation site.

[11] At the same time, two pairs of magnetic sensors record the horizontal vector magnetic field produced by lightning. The ULF/ELF sensors record sferics in a frequency band from $0.1-500 \mathrm{~Hz}$, which measures the several $\mathrm{ms}$ and slower variations in lightning processes, including continuing current [Cummer and Füllekrug, 2001]. The ELF/VLF sensors record signals from $100 \mathrm{~Hz}$ to $25 \mathrm{kHz}$, which captures information at shorter timescales, to several tens of microseconds.

[12] From January 2008 to August 2011, these cameras collectively recorded 1651 sprites. Among these, 6 sprites were produced by negative polarity lightning, which is confirmed by our magnetic field measurements. Figure 1 shows the locations of these 6 sprite-producing lightning. They occurred both over land and ocean. NLDN confirmed their negative polarity with peak current magnitude greater than $102 \mathrm{kA}$. (More details of these events will be discussed 


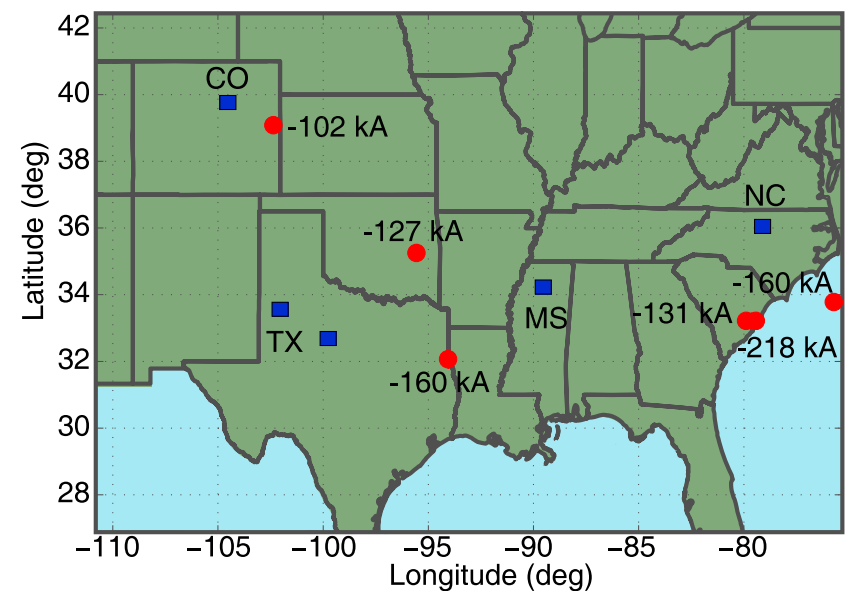

Figure 1. Locations of the 6 sprite-producing -CGs. The blue squared represent stations with optical measurements. The red dots represent the locations of the $6-\mathrm{CGs}$ with labeled NLDN reported peak current.

in the following text and presented in a summary Table in Section 3.5).

[13] By combining measured magnetic fields from the two pairs of magnetic sensors, we extract the lightning source current waveform up to $25 \mathrm{kHz}$ with an improved deconvolution technique that fits both ULF (500 Hz and lower) and VLF (up to $25 \mathrm{kHz}$ ) measurements. With this frequency range, the minimum identifiable risetime is $30 \mu \mathrm{s}$, which is limited by the upper cutoff in the sensor response. Thus the resulting current moment waveform reveal the actual discharging timescale from several tens of microseconds to hundreds of milliseconds and longer. More details about the aforementioned deconvolution technique can be found in [Cummer and Inan, 1997; Cummer, 2003; Li and Cummer, 2012].

[14] We then apply the extracted broadband current source as an input to a 2-D FDTD model [Hu et al., 2006]. This full-wave model computes electric fields as a function of time and location throughout the mesosphere using the source waveform extracted for the event in question. In this work, the initial ionosphere electron density profile was represented by a 2-parameter model with coefficients $(h=85$, $\beta=0.5$ for typical night [Han and Cummer, 2010]. Nonlinear effects, like heating, attachment, and ionization processes, can critically affect the computed electric fields $[\mathrm{Li}$ et al., 2008] and thus have been incorporated in this model. Two sets parameterization of these nonlinear effects have been reported in [Pasko et al., 1997] and [Moss et al., 2006]. Although there is no direct comparison between the accuracy of the two models, we choose the parameterization in [Moss et al., 2006] in our simulation per a private discussion with Ningyu Liu at Florida Institute of Technology, who has successfully achieved valid simulation results with this parameterization [Liu and Pasko, 2004; Liu et al., 2009; Liu, 2010]. It is also worth mentioning that our comparison shows the parameters from the two models are not significantly different, especially for electric fields below the breakdown field. Numerical simulations also show that applying the parameterization in Pasko et al. [1997] does not change our results qualitatively. This is probably because that ionization dominates due to the large field and only a short time period is simulated.

\section{Data Analysis}

[15] In this section, we will analyze three negative sprites in detail before summarizing all 6 events.

\subsection{First Example}

[16] Figure 2a shows a sprite detected on 10/25/2009, 06:52:01 UT. Timing from GPS shows this sprite occurred between $01.226-01.242$ seconds with a $16 \mathrm{~ms}$ exposure time and was visible only in one image. NLDN reported a $-\mathrm{CG}$ at $01.228 \mathrm{sec}$ with a peak current of $-160 \mathrm{kA}$. The lightning location is $33.8212^{\circ} \mathrm{N},-75.2096^{\circ} \mathrm{E}$, which is $426 \mathrm{~km}$ away from the Duke camera. The azimuth location of this lightning discharge, plotted on the sprite image, is within the sprite location. This confirms this - $\mathrm{CG}$ is the sprite-producing event. As mentioned earlier, the offset between sprite and its parent lightning discharge is the cause of the altitude uncertainty. However, in this event and all other events presented in this work, the sprites are not significantly displaced azimuthally from the lightning location. This means they are probably quite close to the lightning location, and thus the altitude uncertainties are probably small for these sprites. Figure $2 \mathrm{~b}$ shows the azimuthal magnetic field in the same time window measured by Duke ELF/VLF and ULF/ ELF sensors. The measured positive azimuthal magnetic field confirms the negative polarity of this lightning discharge. Also there is no other signal appearing in this time window, which further confirms this -CG is the spriteproducing lightning discharge. The measured sferic starts at 01.230 seconds, which bounds the sprite delay between $0-12 \mathrm{~ms}$ from the return stroke.

[17] In the sprite image, the top diffuse region extending from $90 \mathrm{~km}$ down to $76 \mathrm{~km}$ is a halo. The sprite contains multiple elements. In each element, the diffuse top portion is much brighter than the downward streamers, which is consistent with model predictions by Qin et al. [2011]. Downward streamers in this negative sprite terminate at $58 \mathrm{~km}$, which is higher than the termination altitudes for typical positive sprites, usually $40-50 \mathrm{~km}$. This is close to the $60 \mathrm{~km}$ termination altitude of the single negative sprite reported by Taylor et al. [2008]. It is also consistent with the model prediction that negative streamers develop in a smaller region due to the higher critical field compared to positive streamers [Qin et al., 2011].

[18] With the magnetic field measurements, we extracted the full bandwidth lightning source current that is shown in Figure 2c. In this event, the lightning source current has a very fast $(0.5 \mathrm{~ms})$ and large $(-750 \mathrm{C} \mathrm{km})$ charge moment change, with essentially no continuing current that follows. By applying this current source into the 2D FDTD model, we compute the high altitude lightning-driven electric fields directly above the lightning discharge. Figure $2 \mathrm{~d}$ shows the normalized electric fields $\left(E / E_{k}\right)$ directly above the lightning stroke from $40 \mathrm{~km}$ to $90 \mathrm{~km}$ altitude as a function of time. The first $2 \mathrm{~ms}$ are zoomed to show the fast variation of the high altitude fields. The measured altitude ranges of the halo and the negative sprite are plotted as vertical bars in the same plot. In this work, the top and bottom boundary of the optical emission are defined at the locations where the brightness is 
(a) $10 / 25 / 2009$ 06:52:01.226 - 242 UT

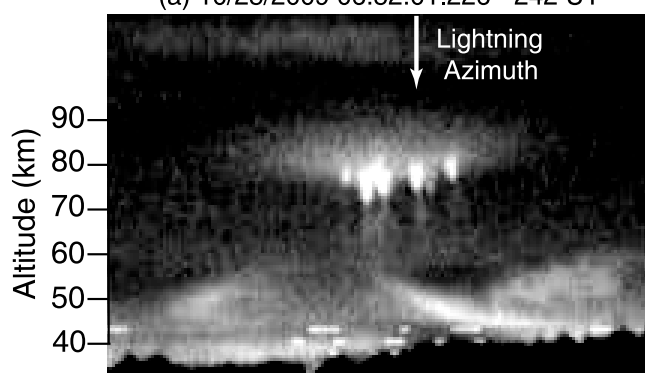

(b)

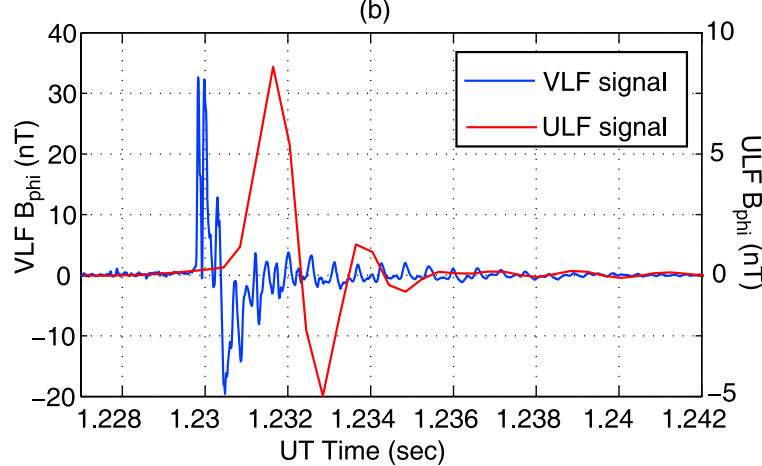

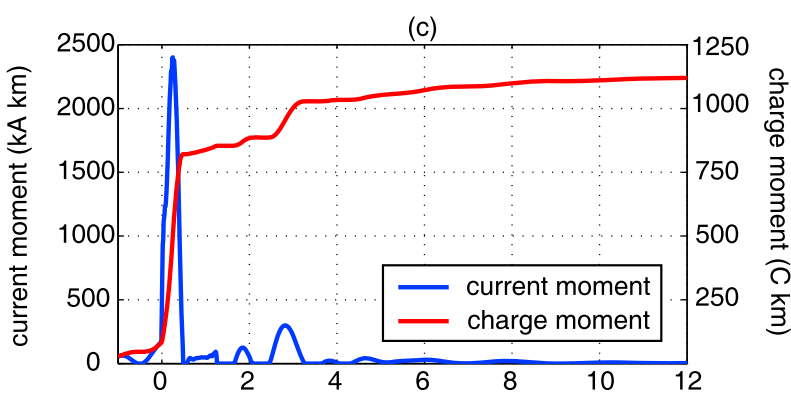

(d)

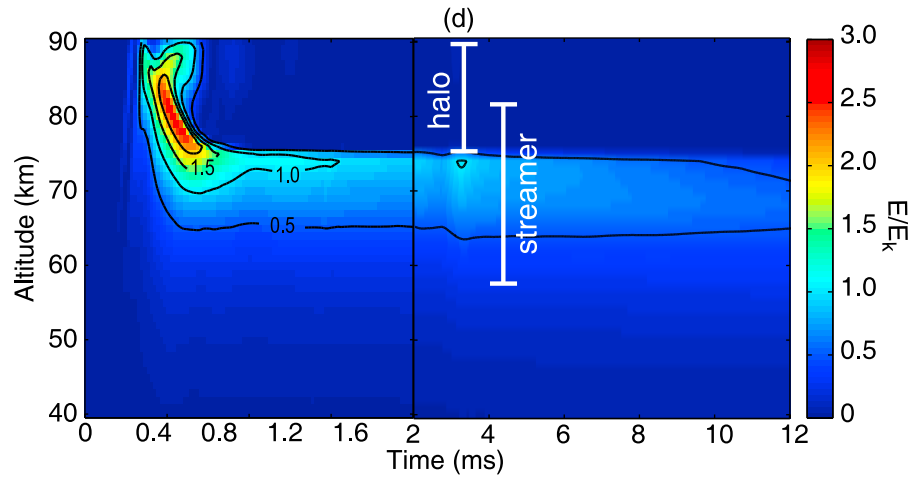

Figure 2. A negative sprite detected on 10/25/2009 06:52:01 UT. (a) Sprite image from WATEC $902 \mathrm{H}$ low light camera. The vertical line represents azimuth location of the lightning discharge. (b) Measured azimuthal magnetic field from Duke ELF/VLF sensor $(100 \mathrm{~Hz}-25 \mathrm{kHz})$ and Duke ULF/ELF sensor $(0.1 \mathrm{~Hz}-500 \mathrm{~Hz})$. (c) Extracted full bandwidth lightning source current waveform and charge moment change history. (d) Normalized lightning-driven electric field from FDTD simulation. Electric fields in the first $2 \mathrm{~ms}$ are zoomed to show the fast changing fields at high altitudes. The vertical bars represent the altitude range of the halo and the sprite.

at least two times greater than the background noise level. Then it is rounded to integer of kilometers. After the lightning discharge, the high field region first appear at the top altitudes from $\sim 75-90 \mathrm{~km}$, which is the altitude range of the halo. The field amplitude is very high with the peak amplitude exceeding $2 E_{k}$. Although the normalized field is very high in this region, it quickly relaxes within a few hundred microseconds due to the high electron density from ionization created by the strong field. Because of their short persistence, these high fields can produce only a halo in this region but can not initiate sprite streamers, which requires a persistence time on the order of milliseconds [Qin et al., 2011].

[19] At lower altitudes from $70-75 \mathrm{~km}$, the high field region of $E>E_{k}$ lasts up to $\sim 1.6 \mathrm{~ms}$, which is capable of initiating sprite streamers in this region. Although the image constrains this negative sprite to $0-12 \mathrm{~ms}$ after the lightning discharge, this field plot indicates that the visible halo should occur at about $0.5 \mathrm{~ms}$ after the lightning discharge and the sprite should occur within a few ms. Below $70 \mathrm{~km}$ altitude, the normalized field shows a much slower variation due to the decrease of ambient electron density. At the observed streamer termination altitude of $58 \mathrm{~km}$, the electric field is $0.23 E_{k}(0.5 \mathrm{~ms})-0.28 E_{k}(12 \mathrm{~ms})$. This termination field is less than the critical field for negative streamer propagation of $0.4 E_{k}$ [Liu et al., 2009], but significantly higher than the termination field for typical positive sprites of $0.05-0.1 E_{k}$ reported by [Li and Cummer, 2012].

\subsection{Second Example}

[20] Figure 3a shows another sprite detected on 08/04/ 2008 at 07:32:59 UT. The GPS timing shows that the sprite occurred between 59.955-59.972 UT. NLDN reported a $-\mathrm{CG}$ at 59.958 seconds UT with a peak current of $-218 \mathrm{kA}$. The lightning discharge occurred at $33.2094^{\circ} \mathrm{N},-79.6345^{\circ} \mathrm{E}$, which is about $310 \mathrm{~km}$ from the camera. The image and the measured magnetic field timing bound the sprite delay to below $12 \mathrm{~ms}$. This sprite is also accompanied with a halo extending from $90 \mathrm{~km}$ down to $70 \mathrm{~km}$ altitude, which is about $5 \mathrm{~km}$ lower than the previous example. The sprite also contains multiple simple-structured elements. Each of the elements has bright upward streamers and dim downward streamers. The downward streamers terminate at about $56 \mathrm{~km}$ altitude, which is again higher than the termination altitudes for typical positive sprites. These features are similar to the previous example in Figure 2.

[21] Figure $3 b$ shows the extracted lightning source current waveform and charge moment change. In this event, the lightning discharge produced a $-1050 \mathrm{C} \mathrm{km}$ charge moment change within $0.5 \mathrm{~ms}$. The computed electric fields show that the lightning source quickly produces high fields in the halo altitudes. However, this high field quickly relaxes and lasts only a few hundred microseconds at each altitude. The electric fields around $70 \mathrm{~km}$ altitude are greater than the breakdown field and last for several ms. At lower altitudes, the electric field shows a much slower variation due to the low ambient electron density. At the termination altitudes 


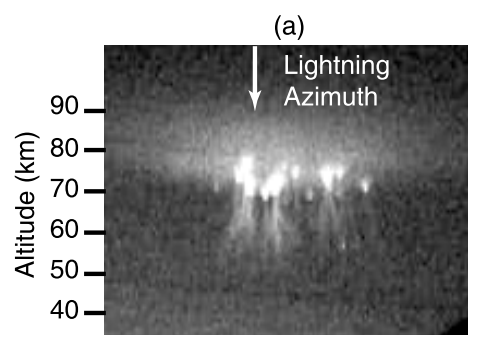

(b)
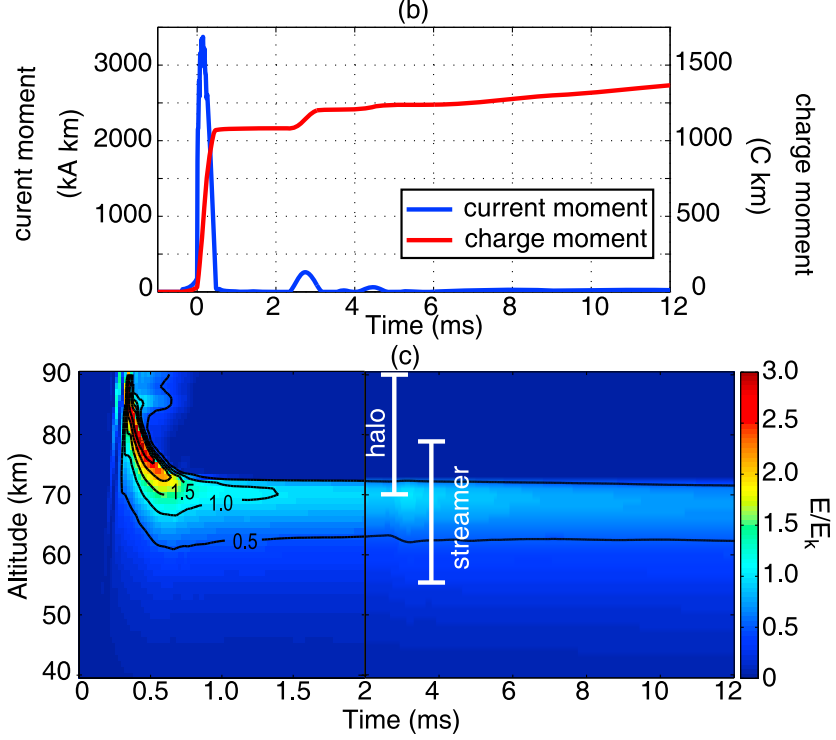

Figure 3. A negative sprite detected on 08/04/2008 07:32:59 UT. (a) Sprite image between 59.955-59.972 seconds. (b) Extracted full bandwidth lightning source current waveform and charge moment change. (c) Normalized lightning-driven electric fields. Electric fields in the first $2 \mathrm{~ms}$ are zoomed. The vertical bars represent the altitude range of the halo and the sprite.

about $56 \mathrm{~km}$, the termination electric field is about $0.24(0.5 \mathrm{~ms})-0.31 E_{k}(12 \mathrm{~ms})$, which is close to the critical field. This example is very similar to the negative sprite shown in Figure 2 in terms of sprite morphology, lightning source current and lightning-driven ambient electric fields.

\subsection{Third Example}

[22] Next, we present a negative sprite with a very dim downward streamer that thus appears to be right at the boundary between a halo and a sprite. Figure 4 a show a sprite and halo occurring on 08/04/2008 between 07:03:29.664 and 29.681 UT. NLDN reported a $-\mathrm{CG}$ at 29.665 seconds with a peak current of $-131 \mathrm{kA}$. The location is at $33.2183^{\circ} \mathrm{N}$, $-79.7995^{\circ} \mathrm{W}$, which is about $312 \mathrm{~km}$ from the camera. The magnetic field measurements bound the sprite delay below $14 \mathrm{~ms}$. This sprite is also accompanied with a halo extending from $90 \mathrm{~km}$ down to $70 \mathrm{~km}$ altitude. The sprite appears at the bottom part of the sprite halo with a simplest structure. The top part appears as a bright spot above $70 \mathrm{~km}$ altitude. Below this bright spot, there is a very dim downward streamer extending to $60 \mathrm{~km}$ altitude, which can be barely seen from the video image.

[23] Figure 4b shows the lightning source current waveform and charge moment change. In this event, the lightning discharge produce $\sim 600 \mathrm{C} \mathrm{km}$ charge moment change within $0.5 \mathrm{~ms}$. Considering the simpleness and dimness of this sprite, the $600 \mathrm{C} \mathrm{km}$ should be close to the threshold to initiate negative streamers under the conditions present at the time. Since the image time resolution can not reveal the precise time of sprite initiation, the actual charge moment change at the sprite initiation could be larger if it occurred more than half ms after the lightning discharge. The computed electric fields show similar pattern with the two events introduced earlier. A very high electric field appears at the top altitudes and quickly relaxes. The normalized electric fields around $74 \mathrm{~km}$ altitude are greater than the breakdown field and last about $4 \mathrm{~ms}$. At the streamer termination altitude of $60 \mathrm{~km}$, the termination electric field is about $0.21(0.5 \mathrm{~ms})-0.29 E_{k}(12 \mathrm{~ms})$, which is also below the critical field. This event again shows the same features as the two examples above except its dimness and the simpler structure.

\subsection{Other Events}

[24] Above we have presented the 3 examples captured by the Duke camera. The other 3 events in our data set were detected at other stations but have the same properties as the Duke events. Thus we show their optical emissions here and summarize the details in the next section. The polarity of

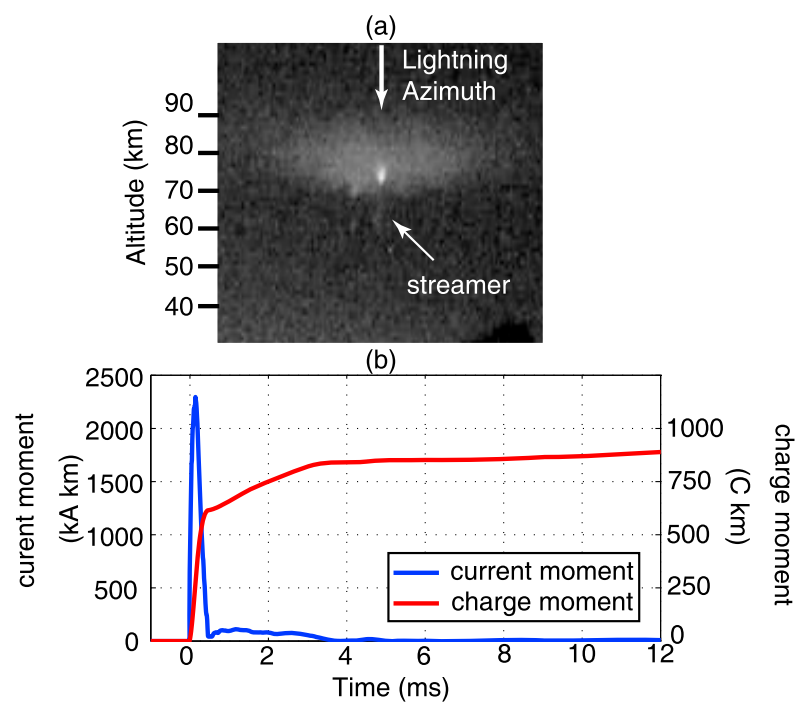

(c)

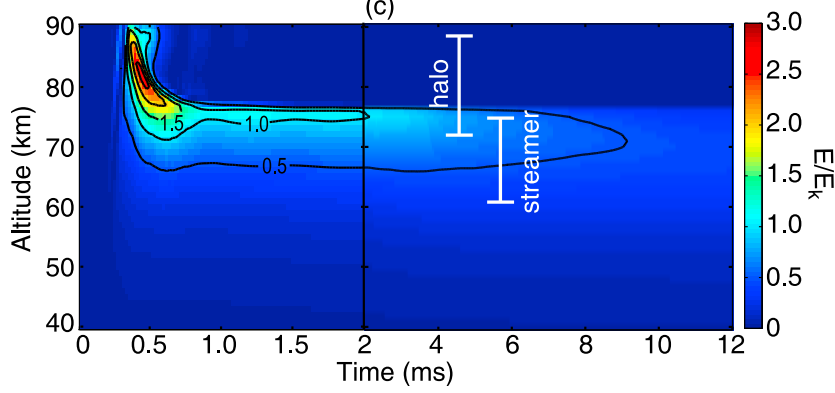

Figure 4. A negative sprite detected on 08/04/2008 07:03:29UT. (a) Sprite image between 29.664-29.681 seconds. (b) Extracted full bandwidth lightning source current waveform and charge moment change. (c) Normalized lightningdriven electric fields. Electric fields in the first $2 \mathrm{~ms}$ are zoomed. The vertical bars represent the altitude range of the halo and the sprite. 

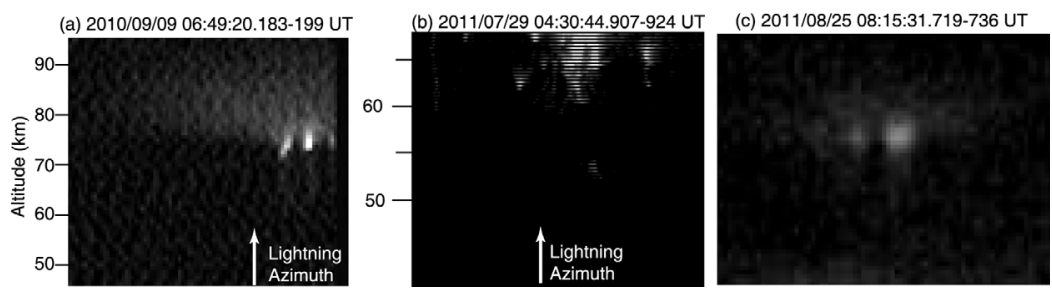

Figure 5. Other negative sprites (a) A negative sprite detected at Hawley, TX. (b) A negative sprite detected at Bennett, CO. (c) A negative sprite detected at Lubbock, TX.

these 3 events also has been confirmed from the polarity of the parent $\mathrm{CG}$ lightning flashes as documented by the NLDN. Figure 5a shows a negative sprite detected at Hawley, TX on 2010/09/09 06:49:20.183-199 UT. The NLDN reported - CG occurred at 06:49:20.189 UT with peak current of $-127 \mathrm{kA}$. This lightning charge moment change is about $650 \mathrm{C} \mathrm{km}$ within $0.6 \mathrm{~ms}$. Similar to the events discussed earlier, this is a short delayed sprite accompanied by a sprite halo. The dim downward streamer terminate at about $62 \mathrm{~km}$ altitude. At this termination altitude, the lightning-driven ambient electric field is $0.24-0.33 E_{k}$. Figure $5 \mathrm{~b}$ shows a negative sprite detected at Bennett, $\mathrm{CO}$ on 2011/07/29 04:30:44.907-924 UT. The sprite-producing -CG occurred at 04:30:44.919 UT with NLDN reported peak current at $-102 \mathrm{kA}$ and a charge moment change of $460 \mathrm{C} \mathrm{km}$. In this event, the sprite image did not include the top portion of the sprite. However, the inferred lightningdriven electric fields also show a very high and quickly relaxing region in $80-90 \mathrm{~km}$ altitude region. Thus it is almost certain that this sprite is also accompanied with a sprite halo. The termination field at $59 \mathrm{~km}$ altitude is $0.17-$ $0.22 E_{k}$. Figure $5 \mathrm{c}$ shows a negative sprite detected at University of Mississippi. Its parent $-\mathrm{CG}$ occurred at 08:15:31.722 UT with peak current of $-160 \mathrm{kA}$ and a charge moment change of $450 \mathrm{C} \mathrm{km}$. The sprite body also contains a sprite halo and dim downward streamers. In this event, we were not able to determine accurately the altitude range of the sprite due to a lack of the background star fields. However, the electric fields at $60 \mathrm{~km}$ altitude is $0.16-0.20 E_{k}$.

\subsection{Summary of Negative Sprite Features}

[25] In our data set, all events show similar features in the presence of a halos, short sprite time delay from the lightning stroke, relatively high streamer termination altitudes, very impulsive lightning source current and high charge transfer, and ambient electric fields. These characteristics are summarized in Table 1 . All the 6 negative sprites are shortdelayed. The GPS timing from the sprite video and magnetic field measurement bound the sprite delay to less than about $10 \mathrm{~ms}$. However, the computed lightning-driven electric field indicates that these negative sprites should occur within a few ms from the return stroke. All the observed sprites accompanied by a sprite halo starting at $\sim 90 \mathrm{~km}$ altitude. The downward streamers terminate from $55-60 \mathrm{~km}$ altitude. These features are also observed in the single event reported in Taylor et al. [2008]. The sprite-producing lightning source current is impulsive and exhibits a big charge moment change greater than $450 \mathrm{C} \mathrm{km}$ within $0.5 \mathrm{~ms}$ duration, and in none of these cases contains significant continuing current. At the streamer termination altitude, the termination field is estimated to be $0.2-0.3 E_{k}$.

\section{Effect of Lightning Discharging Timescale on Transient Electric Fields}

[26] Our results show that negative sprite-producing lightning source current is impulsive and lasts for only $0.5 \mathrm{~ms}$, which is $2-4$ times faster than for typical spriteproducing positive strokes [Hu et al., 2002; Li et al., 2008; $\mathrm{Li}$ and Cummer, 2012]. We now analyze a short source timescale affects the lightning-driven electric fields and sprite morphologies.

[27] Figure 6a shows two lightning source current waveforms with pulse duration of $0.5 \mathrm{~ms}$ and $2 \mathrm{~ms}$. The shape of the waveform was derived from a $-\mathrm{CG}$ and a $+\mathrm{CG}$ both initiating short-delayed sprites. We then scale the two waveforms so that they both produce a charge moment change of $600 \mathrm{C} \mathrm{km}$. Figures $6 \mathrm{~b}$ and $6 \mathrm{c}$ show the corresponding lightning-driven electric fields produced by these two sources. Although the total charge moment change are

Table 1. Summary of Characteristics of 6 Negative Sprites, Including Time; Camera Location, Lightning Range, NLDN Reported Lightning Peak Current $\left(I_{p k}\right)$; Sprite Time Delay $\left(T_{d}\right)$; Whether a Halo is Present; Sprite Altitude Range $(h)$; Lightning Current Pulse Duration $\left(\tau_{\text {lightning }}\right)$; Lightning Charge Moment Change (CMC) in the Main Pulse and at 2 ms; and Streamer Termination Field $\left(E_{\text {ter }}\right)$

\begin{tabular}{|c|c|c|c|c|c|c|c|c|c|c|}
\hline Time (UT) & Camera Loc. & $\begin{array}{c}\text { Range } \\
(\mathrm{km})\end{array}$ & $\begin{array}{c}I_{p k} \\
(\mathrm{kA})\end{array}$ & $\begin{array}{c}T_{d} \\
(\mathrm{~ms})\end{array}$ & $\begin{array}{c}\text { Halo } \\
\text { Present? }\end{array}$ & $\begin{array}{c}h \\
(\mathrm{~km})\end{array}$ & $\begin{array}{l}\tau_{\text {lightning }} \\
(\mathrm{ms})\end{array}$ & $\begin{array}{c}\mathrm{CMC} \\
(\mathrm{C} \mathrm{km})\end{array}$ & $\begin{array}{c}\text { CMC (2 ms) } \\
\quad(\mathrm{C} \mathrm{km})\end{array}$ & $\begin{array}{l}E_{t e r} \\
\left(E_{k}\right)\end{array}$ \\
\hline 2009/10/25 06:52:01 & Duke Univ. & 426 & -160 & $<12$ & yes & $88-58$ & 0.5 & 750 & 800 & $0.23-0.28$ \\
\hline $2008 / 08 / 04$ 07:32:59 & Duke Univ. & 310 & -218 & $<12$ & yes & $90-56$ & 0.5 & 1050 & 1050 & $0.24-0.31$ \\
\hline 2008/08/04 07:03:29 & Duke Univ. & 312 & -131 & $<5$ & yes & $90-60$ & 0.5 & 600 & 720 & $0.21-0.29$ \\
\hline 2010/09/09 06:49:20 & Hawley, TX & 492 & -127 & $<10$ & yes & $90-62$ & 0.6 & 650 & 710 & $0.24-0.33$ \\
\hline 2011/07/29 04:30:44 & Bennett, CO & 202 & -102 & $<15$ & NA & NA-59 & 0.5 & 460 & 560 & $0.17-0.22$ \\
\hline $2011 / 08 / 25$ 08:15:31 & Univ. of Mississippi & 495 & -160 & $<14$ & yes & NA & 0.5 & 450 & 450 & $0.16-0.20^{\mathrm{a}}$ \\
\hline
\end{tabular}

\footnotetext{
${ }^{\mathrm{a}}$ The reported electric field is at $60 \mathrm{~km}$ altitude for the Mississippi event, in which the termination altitude can not be estimated due to a lack of
} background star fields. 

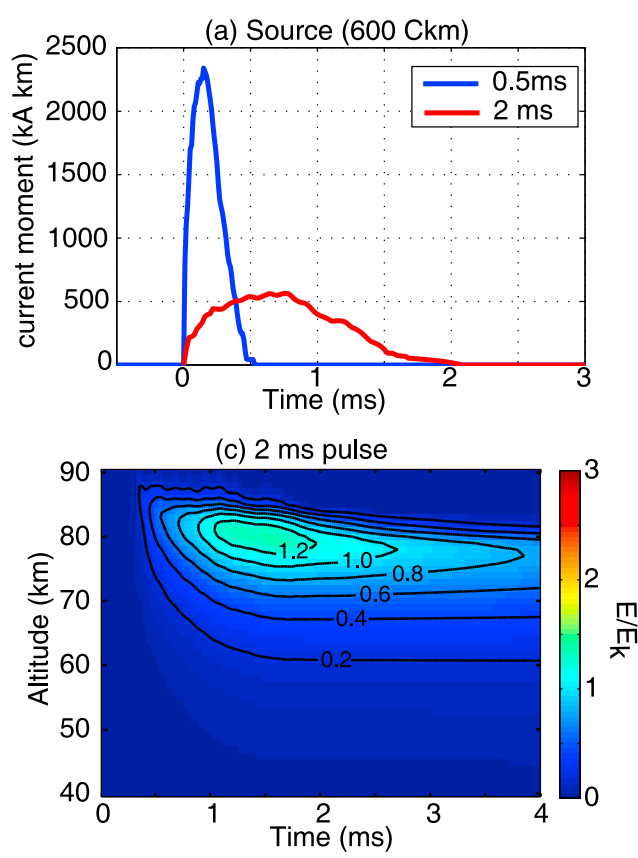

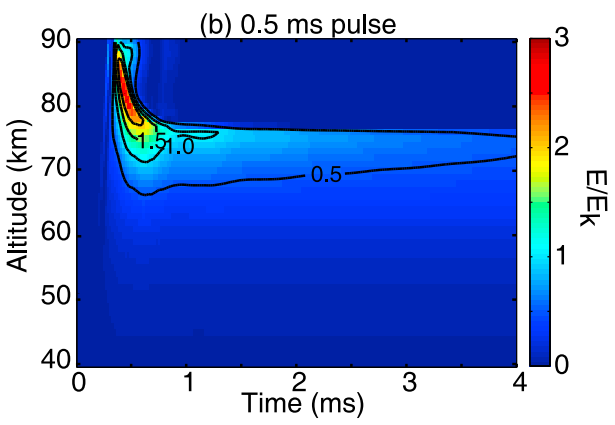

(d) High field persistence

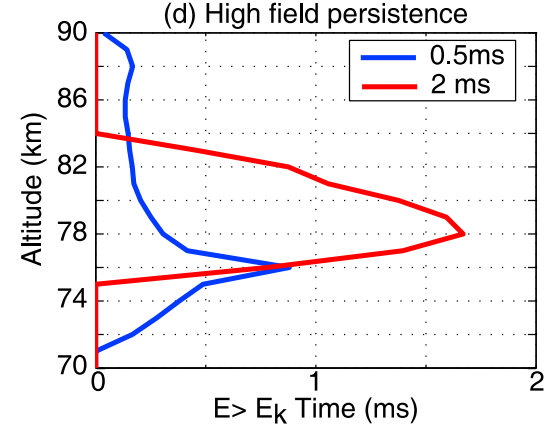

Figure 6. Effect of different discharging timescale on lightning-driven electric fields. (a) Two $600 \mathrm{C} \mathrm{km}$ current moment source with pulse duration of $0.5 \mathrm{~ms}$ and $2 \mathrm{~ms}$. (b) Lightning-driven electric fields produced with the impulsive source ( $0.5 \mathrm{~ms}$ duration). (c) Lightning-driven electric fields with the $2 \mathrm{~ms}$ pulse source. (d) Persistent time of high field region $\left(E>E_{k}\right)$.

the same in both cases, there is a significant difference between their associated lightning-driven electric fields.

[28] In Figure 6b, the scenario is similar to the fields associated with the negative sprites. The peak field appears at $90 \mathrm{~km}$ altitude and descends to $75 \mathrm{~km}$ altitude with high amplitude about 1.5-2.0 $E_{k}$. This field is high enough to produce a visible halo but can not initiate sprite streamers due to its quick relaxation. Normalized electric fields further decrease as altitudes. Around $76 \mathrm{~km}$ altitude, the field is still higher than $E_{k}$ and persists close to $1 \mathrm{~ms}$, which is sufficient to initiate streamers. For the electric fields produced by the $2 \mathrm{~ms}$ pulse, the peak electric fields appears at a lower altitude around $80 \mathrm{~km}$. Although the peak amplitude $\left(\sim 1.2-1.4 E_{k}\right)$ is smaller than that from the $0.5 \mathrm{~ms}$ pulse $\left(1.5-2.0 E_{k}\right)$, the high field persists for a longer time. Since initiating a sprite streamer requires both a field greater than $E_{k}$ and a persistent time in ms scale, the latter case is potentially more favorable to form streamers.

[29] Figure 6d explicitly shows the persistence time of $E>E_{k}$ at different altitudes for both cases. In the altitude range of 76-84 $\mathrm{km}$ range, the high field from the $2 \mathrm{~ms}$ pulse persists significantly longer than that from the narrower pulse. This altitude range is consistent with the sprite streamer initiation region. This longer high field persistence time indicates that streamers may be more easily formed in the case of $2 \mathrm{~ms}$ source pulse. Also streamers can be initiated over a larger range of altitude, helping a sprite develop into more complicated structures. Although the field amplitude and duration are critical in sprite streamer initiation, formation of sprite streamers also depends on other highly nonlinear processes, i.e. local ionization patches [Liu and Pasko, 2004; Liu et al., 2012; Qin et al., 2011; Kosar et al., 2012].
Thus this hypothesis will require a test by the existing fluid models.

\section{Conclusions}

[30] We have reported 6 negative polarity sprites observed from 4 different sites that were the only negative sprites among a total of 1651 sprites recorded by 5 cameras distributed throughout the US. Their polarity has been confirmed by both the NLDN and magnetic field measurements. These 6 sprites and the single event previously reported by Taylor et al. [2008] show remarkably similar morphology, including an accompanying bright halo, relatively simple streamer structure, and streamer termination altitudes measurably higher (at and above $55 \mathrm{~km}$ ) than for positive polarity sprites. These observations suggest that negative sprites may always look like this and may not exhibit the variable structure of their positive counterparts. In Table 2,

Table 2. Comparison of Negative Sprites With Positive Sprites in Their Morphology, Lightning Source Current, and LightningDriven Electric Fields

\begin{tabular}{lccc}
\hline & $\begin{array}{c}\text { Feature } \\
\text { Delay }\end{array}$ & $\begin{array}{c}\text { Negative } \\
\text { a Few ms }\end{array}$ & $\begin{array}{c}\text { Positive } \\
\text { Highly Variable }\end{array}$ \\
\hline Morphology & Halo & always & Not always \\
& Altitude range $(\mathrm{km})$ & $55-90$ & $40-90$ \\
Lightning & Structure & always same & highly variable \\
source & Pulse duration & $0.5 \mathrm{~ms}$ & $1-2 \mathrm{~ms}$ \\
Lightning-driven & CMC $(\mathrm{C} \mathrm{km})$ & $>450$ & $>300$ \\
electric fields & Strength & Very high & High \\
& Persistence & short & longer \\
& Streamer termination $\left(E_{k}\right)$ & $0.2-0.3$ & $0.05-0.1$ \\
\hline
\end{tabular}


we contrast the features and details of positive and negative polarity sprites.

[31] With an improved deconvolution technique that combines magnetic field measurements over a $0.1 \mathrm{~Hz}$ to $25 \mathrm{kHz}$ bandwidth, we extract the lightning source current waveform over a range of timescales from several tens of $\mu \mathrm{s}$ to hundreds of ms. The results show that negative sprites are produced by very impulsive lightning current with charge moment changes greater than $450 \mathrm{C} \mathrm{km}$ in $0.5 \mathrm{~ms}$ or less. Essentially no continuing current is observed following this fast charge transfer. This indicates that high charge moment change negative lightning strokes may all follow similar timescales and lack significant continuing current. This uniformity of lightning characteristics probably explains the uniformity of negative sprite morphology.

[32] For all the negative sprites analyzed, the negative downward streamers terminate at $55-60 \mathrm{~km}$ altitude, where the lightning-driven ambient electric field is about $0.2-0.3 E_{k}$. This is slightly below the critical field of $0.4 E_{k}$ to sustain negative streamer propagation. We also compare these termination altitudes and fields with positive sprites presented in $\mathrm{Li}$ and Cummer [2012]. In typical positive sprites, positive downward streamers terminate at $40-50 \mathrm{~km}$ altitude, where the lightning-driven ambient electric field is about $0.05-0.1 E_{k}$. These values are also slightly below the critical field of $0.16 E_{k}$ for positive streamers. Although it is generally agree that streamers should quickly stop after reaching their critical fields, the results show that both negative and positive downward streamers can propagate to locations where the lightning-driven ambient field is below the their critical fields by a factor of $\sim 2-3$. The closeness of the two ratios indicates that the critical field, although higher than the termination field, still play an important role in the streamer termination.

[33] Simulations show that a fast source timescale has a great impact on the high altitude electric fields and further the sprite initiation and morphology. Comparing narrow $(0.5 \mathrm{~ms})$ and wider $(2.0 \mathrm{~ms})$ source pulses with the same charge moment change, numerical simulations show that a $0.5 \mathrm{~ms}$ pulse produces a very high peak electric field at 75-90 km altitudes, which is the reason that all negative sprites are accompanied with halos. On the other hand, the high fields produced by a fast source also relax more quickly due to extra ionization created by the high fields. Thus the high field may not be able to persist long enough to form sprite streamers.

[34] In contrast, the slower pulse can produces a high field region of $E>E_{k}$ with a longer persistence time, which provides a more favorable condition to initiate sprite streamers. This could be the reason that positive sprites are easier to initiate and more often develop into complicated structures. Although the field amplitude and duration are critical in sprite streamer initiation, formation of sprite streamers also depends on other highly nonlinear processes, i.e. local ionization patches [Liu and Pasko, 2004; Qin et al., 2011]. Thus this hypothesis will require a test by the existing fluid models.

[35] Previous studies have shown that -CGs generally associate with more impulsive lighting source current than +CGs [Gomes and Cooray, 1998]. Our simulations show that it is more difficult to initiate sprite streamers for an impulsive source with the same amount of charge transfer.
This implies that the charge moment change required to initiate negative sprites is more than that for positive sprites. This is also consistent with previous observations showing the rareness of negative sprites but a much higher occurrence rate of negative halos, which does not require a long duration of high fields. Furthermore, while even an impulsive source is capable of forming streamers when the charge moment change is large enough, these streamers can only initiate in a region of limited vertical extent. Thus negative sprites may not be able to develop into complicated structures.

[36] Acknowledgments. We would like to acknowledge below colleagues who operate or assist us in operating the low-light cameras for the sprite observation: Walter Lyons at FMA Research Inc.; Kevin Palivec at Hawley, TX; Sumedhe Karunarathne and Thomas Marshall at University of Mississippi; Tim Saramas at Bennett, CO; and Eric Bruning at Texas Tech University. We also thank Ningyu Liu at Florida Institute of Technology for the private discussion in choosing the parameterization in numerical simulations. This work was supported by the NSF Physical and Dynamic Meteorology Program, the NSF Aeronomy Program, and the DARPA NIMBUS Program.

[37] Robert Lysak thanks the reviewers for their assistance in evaluating this paper.

\section{References}

Asano, T., M. Hayakawa, M. G. Cho, and T. Suzuki (2008), Computer simulations on the initiation and morphological difference of Japan winter and summer sprites, J. Geophys. Res., 113, A02308, doi:10.1029/ 2007JA012528.

Asano, T., T. Suzuki, Y. Hiraki, E. Mareev, M. G. Cho, and M. Hayakawa (2009), Computer simulations on sprite initiation for realistic lightning models with higher-frequency surges, J. Geophys. Res., 114, A02310, doi:10.1029/2008JA013651.

Barrington-Leigh, C. P., U. S. Inan, and M. Stanley (2001), Identification of sprites and elves with intensified video and broadband array photometer, J. Geophys. Res., 106(A2), 1741-1750, doi:10.1029/2000JA000073.

Bering, E. A., et al. (2004), Observations of transient luminous events (TLEs) associated with negative cloud to ground (-CG) lightning strokes, Geophys. Res. Lett., 31, L05104, doi:10.1029/2003GL018659.

Cummer, S. A. (2003), Current moment in sprite-producing lightning, J. Atmos. Sol. Terr. Phys., 65, 499-508.

Cummer, S. A., and M. Füllekrug (2001), Unusually intense continuing current in lightning causes delayed mesospheric breakdown, Geophys. Res. Lett., 28(3), 495-498, doi:10.1029/2000GL012214.

Cummer, S. A., and U. S. Inan (1997), Measurement of charge transfer in sprite-producing lightning using ELF radio atmospherics, Geophys. Res. Lett., 24(14), 1731-1734, doi:10.1029/97GL51791.

Cummer, S. A., and W. A. Lyons (2005), Implications of lightning charge moment changes for sprite initiation, J. Geophys. Res., 110, A04304, doi:10.1029/2004JA010812.

Cummer, S. A., N. Jaugey, J. Li, W. A. Lyons, T. E. Nelson, and E. A. Gerken (2006), Submillisecond imaging of sprite development and structure, Geophys. Res. Lett., 33, L04104, doi:10.1029/2005GL024969.

Frey, H. U., et al. (2007), Halos generated by negative cloud-to-ground lightning, Geophys. Res. Lett., 34, L18801, doi:10.1029/2007GL030908. Gerken, E. A., and U. S. Inan (2002), A survey of streamer and diffuse glow dynamics observed in sprites using telescopic imagery, J. Geophys. Res. 107(A11), 1344, doi:10.1029/2002JA009248.

Gerken, E. A., U. S. Inan, and C. P. Barrington-Leigh (2000), Telescopic imaging of sprites, Geophys. Res. Lett., 27(17), 2637-2640, doi:10.1029/ 2000 GL000035.

Gomes, C., and V. Cooray (1998), Long impulse currents associated with positive return strokes, J. Atmos. Sol. Terr. Phys., 60, 693-699.

Han, F., and S. A. Cummer (2010), Midlatitude nighttime d region ionosphere variability on hourly to monthly time scales, J. Geophys. Res., 115, A09323, doi:10.1029/2010JA015437.

Hu, W., S. A. Cummer, W. A. Lyons, and T. E. Nelson (2002), Lightning charge moment changes for the initiation of sprites, Geophys. Res. Lett., 29(8), 1279, doi:10.1029/2001GL014593.

Hu, W., S. A. Cummer, W. A. Lyons, and T. E. Nelson (2006), An FDTD model for low and high altitude lightning-generated EM fields, IEEE Trans. Antennas Propag., 54(5), 1513-1522.

Huang, E., E. Williams, R. Boldi, S. Heckman, W. Lyons, M. Taylor, T. Nelson, and C. Wong (1999), Criteria for sprites and elves based 
on schumann resonance observation, J. Geophys. Res., 104(D14), 16,943-16,964, doi:10.1029/1999JD900139.

Kosar, B. C., N. Liu, and H. K. Rassoul (2012), Luminosity and propagation characteristics of sprite streamers initiated from small ionospheric disturbances at subbreakdown conditions, J. Geophys. Res., 117, A08328, doi:10.1029/2012JA017632.

Li, J., and S. A. Cummer (2009), Measurement of sprite streamer acceleration and deceleration, Geophys. Res. Lett., 36, L10812, doi:10.1029/ 2009GL037581.

Li, J., and S. Cummer (2012), Relationship between sprite streamer behavior and lightning-driven electric fields, J. Geophys. Res., 117, A01317, doi: $10.1029 / 2011 \mathrm{JA} 016843$.

Li, J., S. A. Cummer, W. A. Lyons, and T. E. Nelson (2008), Coordinated analysis of delayed sprites with high-speed images and remote electromagnetic fields, J. Geophys. Res., 113, D20206, doi:10.1029/2008JD010008.

Liu, N. (2010), Model of sprite luminous trail caused by increasing streamer current, Geophys. Res. Lett., 37, L04102, doi:10.1029/2009GL042214.

Liu, N., and V. P. Pasko (2004), Effects of photoionization on propagation and branching of positive and negative streamers in sprites, J. Geophys. Res., 109, A04301, doi:10.1029/2003JA010064.

Liu, N. Y., V. P. Pasko, K. Adams, H. C. Stenbaek-Nielsen, and M. G. McHarg (2009), Comparison of acceleration, expansion, and brightness of sprite streamers obtained from modeling and high-speed video observations, J. Geophys. Res., 114, A00E03, doi:10.1029/ 2008JA013720.

Liu, N. Y., B. Kosar, S. Sadighi, J. R. Dwyer, and H. K. Rassoul (2012), Formation of streamer discharges from an isolated ionization column at subbreakdown conditions, Phys. Rev. Lett., 109, 025002.

Lu, G., S. A. Cummer, R. J. Blakeslee, S. Weiss, and W. H. Beasley (2012), Lightning morphology and impulse charge moment change of high peak current negative strokes, J. Geophys. Res., 117, D04212, doi:10.1029/ 2011JD016890.

Lyons, W. A. (1996), Sprite observation above the U.S. high plains in relation to their parent thunderstorms, J. Geophys. Res., 101(D23), 29,641-29,652, doi:10.1029/96JD01866.

McHarg, M. G., H. C. Stenbaek-Nielsen, and T. Kammae (2007), Observations of streamer formation in sprites, Geophys. Res. Lett., 34, L06804, doi:10.1029/2006GL027854.

Moss, G. D., V. P. Pasko, N. Liu, and G. Veronis (2006), Monte Carlo model for analysis of thermal runaway electrons in streamer tips in transient luminous events and streamer zones of lightning leaders, J. Geophys. Res., 111, A02307, doi:10.1029/2005JA011350.

Newsome, R. T., and U. S. Inan (2010), Free-running ground-based photometric array imaging of transient luminous events, J. Geophys. Res., 115 A00E41, doi:10.1029/2009JA014834.
Pasko, V., U. Inan, and T. Bell (1998), Spatial structure of sprites, Geophys. Res. Lett., 25(12), 2123-2126, doi:10.1029/98GL01242.

Pasko, V. P., U. S. Inan, and T. F. Bell (1997), Sprite produced by quasielectrostatic heating and ionization in the lower ionosphere, J. Geophys. Res., 102(A3), 4529-4561, doi:10.1029/96JA03528.

Pasko, V. P., U. S. Inan, and T. F. Bell (2000), Fractal structure of sprites, Geophys. Res. Lett., 27(4), 497-500, doi:10.1029/2001GL014241.

Qin, J., S. Celestin, and V. P. Pasko (2011), On the inception of streamers from sprite halo events produced by lightning discharge with positive and negative polarity, J. Geophys. Res., 116, A06305, doi:10.1029/ 2010JA016366,

Sentman, D. D., E. M. Wescott, D. L. Osborne, D. L. Hampton, and M. J. Heavner (1995), Preliminary results from the Sprites94 Aircraft Campaign: 1. Red sprites, Geophys. Res. Lett., 22(10), 1205-1208, doi:10.1029/95GL00583.

Stanley, M. S., P. Krehbiel, M. Brook, C. Moore, W. Rison, and B. Abrahams (1999), High speed video of initial sprite development, Geophys. Res. Lett., 26(20), 3201-3204, doi:10.1029/1999GL010673.

Stanley, M. S., M. Brook, P. Krehbiel, and S. A. Cummer (2000), Detection of daytime sprites via a unique sprite ELF signature, Geophys. Res. Lett. 27(6), 871-874, doi:10.1029/1999GL010769.

Stenbaek-Nielsen, H., D. R. Moudry, E. M. Wescott, D. D. Sentman, and F. T. S. Sabbas (2000), Sprites and possible mesospheric effect, Geophys. Res. Lett., 27(23), 3829-3832, doi:10.1029/2000GL003827.

Taylor, M. J., et al. (2008), Rare measurements of a sprite with halo event driven by a negative lightning discharge over Argentina, Geophys. Res. Lett., 35, L14812, doi:10.1029/2008GL033984.

Wescott, E. M., D. D. Sentman, M. J. Heavner, D. L. Hampton, and W. A. Lyons (1998), Columniform sprites: A different variety of mesospheric optical flashes, J. Atmos. Sol. Terr. Phys., 60, 10,467-10,477.

Wescott, E. M., H. C. Stenbaek-Nielsen, D. D. Sentman, M. J. Heavner, D. R. Moudry, and F. T. S. Sabbas (2001), Triangulation of sprites, associated halos and their possible relation to causative lightning and micrometeors, J. Geophys. Res., 106(A6), 10,467-10,477, doi:10.1029/ 2000JA000182.

Williams, E., E. Downes, R. Boldi, W. Lyons, and S. Heckman (2007), Polarity asymmetry of sprite-producing lightning: A Paradox?, Radio Sci., 42, RS2S17, doi:10.1029/2006RS003488.

Williams, E., et al. (2012), Resolution of the sprite polarity paradox: The role of halos, Radio Sci., 47, RS2002, doi:10.1029/2011RS004794.

Williams, E. R. (2006), Problems in lightning physics the role of polarity asymmetry, Plasma Sour. Sci. Technol., 15, S91-S108, doi:10.1088/ 0963-0252/15/2/S12.

Wilson, C. T. R. (1925), The acceleration of $\beta$-particles in strong electric fields such as those in thunderclouds, Proc. Cambridge Philos. Soc., $22,534-538$. 